\title{
Article
}

\section{Wollastonite to Improve Fire Properties in Medium-Density Fiberboard Made from Wood and Chicken Feather Fibers}

\author{
Hamid R. Taghiyari 1,*(D), Jeffrey J. Morrell ${ }^{2}$ and Antonios N. Papadopoulos ${ }^{3, * \mathbb{D}}$ \\ 1 Wood Science and Technology Department, Faculty of Materials Engineering \& New Technologies, \\ Shahid Rajaee Teacher Training University, Tehran 16788-15811, Iran \\ 2 National Center for Timber Durability and Design Life, University of Sunshine Coast, \\ Brisbane, QLD 4102, Australia; jmorrell@usc.edu.au \\ 3 Laboratory of Wood Chemistry and Technology, Department of Forestry and Natural Environment, \\ International Hellenic University, GR-661 00 Drama, Greece \\ * Correspondence: htaghiyari@sru.ac.ir (H.R.T.); antpap@for.ihu.gr (A.N.P.)
}

check for updates

Citation: Taghiyari, H.R.; Morrell, J.J.; Papadopoulos, A.N. Wollastonite to Improve Fire Properties in Medium-Density Fiberboard Made from Wood and Chicken Feather Fibers. Appl. Sci. 2021, 11, 3070. https://doi.org/10.3390/app11073070

Academic Editor: Giuseppe Lazzara

Received: 18 March 2021

Accepted: 29 March 2021

Published: 30 March 2021

Publisher's Note: MDPI stays neutral with regard to jurisdictional claims in published maps and institutional affiliations.

Copyright: (c) 2021 by the authors. Licensee MDPI, Basel, Switzerland. This article is an open access article distributed under the terms and conditions of the Creative Commons Attribution (CC BY) license (https:// creativecommons.org/licenses/by/ $4.0 /)$.

\begin{abstract}
Poultry is a crucial global protein source.However, processing creates sizable quantities of feathers as a by-product. Identifying suitable uses for these feathers poses a major challenge. One possible use would be as an extender in medium density fiberboards (MDF). At the same time, feathers might also modify the inherent fire resistance of the resulting panels, suggesting the need for additives to enhance fire performance. The potential for using feathers to supplement wood in MDF panels was evaluated in conjunction with the addition of wollastonite. The effects of using $5 \%$ or $10 \%$ feathers with or without $10 \%$ wollastonite were investigated. Adding $5 \%$ feathers did affect properties. However, simultaneous addition of $10 \%$ wollastonite resulted in panels with improved fire performance properties and increased the ability of panels to dissipate heat. The results suggest that feathers could be a resource for extending timber supplies for MDF production, especially with wollastonite to improve fire performance.
\end{abstract}

Keywords: fire-retarding properties; medium-density fiberboard (MDF); piloted flame; wollastonite

\section{Introduction}

Medium density fibreboard (MDF) is an important product in a variety of industries ranging from low-cost furniture to exterior protected panels. MDF is most commonly produced using wood particles produced as by-products from other operations but can be produced from a variety of other agricultural by-products. However, wood fiber is not always available, and there is a continuing search for alternative materials for these products.

One possible alternative material would be feathers from poultry production. Global chicken production results in an estimated 40 million tonnes of feathers as a by-product [1]. A variety of methods have been proposed for processing feathers, including steam explosion to create new feed sources and composting, but most approaches are technologically difficult [1]. At present, there are relatively few practical avenues for processing of these materials. As a result, much of this material is sent to landfills or burned. Identifying processing pathways for feathers would reduce pressure on landfills while helping to extend global wood resources.

Chicken feathers have been successfully incorporated into MDF as well as particleboard [2,3], but the effects of feathers on fire performance have not been studied.

Feathers are largely composed of keratin, which has some ability to limit flammability by creating a carbon layer on the surface, much in the same way as wood. Thus, supplementing wood panels with feathers may also behave similarly to wood in terms of flammability of the resulting product. At the same time, addition of low-cost fire retardants could help to further improve panel properties. One candidate is wollastonite $\left(\mathrm{CaSiO}_{3}\right)$, 
a naturally occurring mineral that has previously been shown to enhance resin curing and improve fire performance [4-8]. Combining feathers and wollastonite might create a pathway for utilizing feathers while improving panel properties.

The objective of this study was to explore the effects of incorporating small amounts of chicken feathers and wollastonite on subsequent fire performance of MDF panels.

\section{Materials and Methods}

\subsection{Panel Production and Specimen Preparation}

Wood fibers (containing Fagus spp., Alnus spp., Acer spp., Carpinus spp., and Populus spp.) were procured from SanayeChoobeKhazar Company (MDF Caspian Khazar, Amol, Iran). The materials were oven dried and weighed to determine an initial moisture content.

Feathers were procured from a local farm and were extensively washed prior to use. Although separation of the quills from the feathers would create a more uniform material, this process would be costly. Instead, whole feathers from the body were used, except that wing feathers were excluded. The materials were shredded prior to use and then oven dried.

The wood materials were blended with 5 or $10 \%$ feathers and thoroughly mixed prior to use. The resulting mixtures of wood and feathers were blended with $10 \%(\mathrm{wt} / \mathrm{wt})$ of urea formaldehyde resin (Pars Chemical Co., Tehran, Iran). The resin had a viscosity of 200-400 cP, a 47 second gel time and a density of $1.277 \mathrm{~g} / \mathrm{cm}^{3}$. Wollastonite gel (Mehrabadi Manufacturing Company, Tehran, Iran) containing $90 \%$ micron-sized wollastonite particles (1-4 $\mu \mathrm{m}$ wide by 5 to $25 \mu \mathrm{m}$ long were added to the UF resin $(10 \% \mathrm{wt} / \mathrm{wt})$. The mixture was thoroughly blended for $20 \mathrm{~min}$. The resin, with and without wollastonite, was sprayed on the tumbling wood/feather fibers in a rotary drum.

The mixtures were used to press $16 \mathrm{~mm}$ thick panels at a pressure of $16 \mathrm{MPa}$ and $175{ }^{\circ} \mathrm{C}$ for $6 \mathrm{~min}$ to a target density of $0.67 \mathrm{~g} / \mathrm{cm}^{3}$. In order that all panels reach equilibrium moisture content similar to what they would be in service, and when were used to manufacture cabinets, all resulting five panels per variable were trimmed and conditioned for four weeks at $25^{\circ} \mathrm{C}$ and $40 \pm 3 \%$ relative humidity. This way, their fire properties could be better evaluated in practice, and as panels used under practical conditions at the home and office. Moisture content at the time of testing was $7.5 \pm 0.5 \%$ in all treatments. Small differences in moisture content can have major effects on fire properties [9]. Though moisture contents at the core and surface layers of each composite panel might be different, it could be assumed that all panels had similar moisture contents and similar moisture gradients, becauseall panels were produced under the same conditions and with the same materials.

\subsection{Fire Performance}

The fire performance of the panels was assessed using a previously described slide fire test apparatus (SFTA) which was placed in a three-wall compartment that limited movement of air. A flame was applied through a Bunsen-type burner at a $45^{\circ}$ angle for $120 \mathrm{~s}$ (based on requirements of standard ISO 11925-3) [10] and the times to ignition, as well as glowing, were recorded. Samples were weighed before and after exposure to calculate weight loss. The duration of time that a visible flame was observed on specimens was recorded, and then the length and width of the char area were measured.

\subsection{Statistical Analysis}

A two-way analysis of variance (ANOVA) was carried out using SAS software (9.2; 2010), for each fire property at the $95 \%$ level of confidence. Hierarchical cluster analysis was performed by SPSS (version $18 ; 2010$ ) to categorize treatments based on time to ignition, time to glow, weight loss, duration of flame and char area. 


\section{Results and Discussion}

\subsection{Time to Ignition}

MDF with 10\% feathers had the shortest time to ignition, followed by MDF with 5\% feathers. The addition of wollastonite to the feather amended MDF increased ignition time, but both treatments still ignited in a shorter time than either MDF alone or amended with wollastonite (Table 1). The results indicated that feathers accelerated ignition, and that this could be partially offset by wollastonite addition.

Table 1. Effects of addition of chicken feathers and wollastonite on the fire behaviour of medium density fibreboard ${ }^{\mathrm{a}}$.

\begin{tabular}{|c|c|c|c|c|c|c|}
\hline \multirow{2}{*}{ Feathers $(\% w t / w t)$} & \multirow{2}{*}{ Wollastonite } & \multicolumn{3}{|c|}{ Time to Onset of (Seconds) } & \multirow{2}{*}{ Char Area $\left(\mathrm{mm}^{2}\right)$} & \multirow{2}{*}{ Weight Loss $(\%)$} \\
\hline & & Ignition & Glowing & Flame Time & & \\
\hline 0 & - & 51 (6) CD & 76 (6) B & $1.0(0.2) \mathrm{B}$ & 3050 (290) & $1.8(0.4) \mathrm{CD}$ \\
\hline 0 & + & 64 (3) A & 99 (4) $\mathrm{AB}$ & $1.3(0.1) \mathrm{B}$ & $3020(220)$ & $1.2(0.4) \mathrm{D}$ \\
\hline 5 & - & 48 (8) B & 91 (10) AB & $1.1(0.5) \mathrm{B}$ & $2800(300)$ & $2.9(0.3) \mathrm{B}$ \\
\hline 5 & + & 51 (4) B & $106(9) \mathrm{A}$ & $1.1(0.3) \mathrm{B}$ & $2830(280)$ & $2.3(0.2) \mathrm{C}$ \\
\hline 10 & - & 35 (11) D & 83 (12) B & $3.1(0.9) \mathrm{A}$ & $3400(400)$ & $4.1(0.5) \mathrm{A}$ \\
\hline 10 & + & 53 (5) B & 92 (9) $\mathrm{AB}$ & $2.7(0.6) \mathrm{A}$ & $2940(360)$ & $3.2(0.3) \mathrm{B}$ \\
\hline
\end{tabular}

${ }^{\text {a }}$ Values represent means of five replicates per treatment while figures in parentheses represent one standard deviation. Values followed by the same letter(s) do not differ significantly from each other by a Duncan's multiple range test $\left(\alpha^{\prime}=0.05\right)$. Char area values did not differ significantly from each other.

\subsection{Time to Glow}

The time to glow provides a measure of how rapidly fire gains intensity. Wood-based MDF had the shortest time to glow, followed by MDF with $10 \%$ feathers alone or amended with wollastonite. MDF amended with wollastonite or MDF with $5 \%$ feathers with or without wollastonite took longer to glow.

\subsection{Duration of Burning}

The development of a char layer on the MDF surface should lead to self-extinction unless new material beneath the char is exposed. Thus, prolonged burning is an indicator that the material will tend to be more susceptible to fire. Interestingly, MDF alone, or MDF amended with feathers with or without wollastonite, had similar burn times, while MDF with wollastonite had a slightly longer burn time but did not differ significantly from the MDF alone. The addition of $10 \%$ feathers was associated with significantly longer burn times, although the addition of $10 \%$ wollastonite was associated with a slight reduction. The results suggest that the higher feather level negatively affected fire performance, even with the addition of a fire retardant.

\subsection{Char Area}

While there were slight differences in char area on the various panels, none of the differences were significant. The lack of difference may have reflected the method of flame application, which tended to produce a uniform area of charring.

\subsection{Weight Losses}

Weigh losses were highest for the 10\% feather MDF with or without wollastonite, closely followed by the $5 \%$ feather amended panels. MDF with wollastonite experienced the lowest weight losses, followed closely by panels with MDF alone or MDF with 5\%feathers and wollastonite. The results indicate that the addition of wollastonite improvedthe fire properties of MDF but also helped to mitigate the effects of $5 \%$ feather addition.

The negative effects of feathers on panel fire performance likely reflect the lack of integration between the resin, wood and feathers [3], resulting in a tendency for feather elements near the surface to ignite and expose more material beneath.

Previous studies reported high and statistically significant R-squared values between different fire properties, such as time to onset of ignition and time to glowing $[4,8]$. In the present study, however, R-squared values between the properties was low and statistically 
insignificant. In this regard, though a general relationship among fire properties was observed, there was inconsistency in the whole trend. The inconsistency was attributed to the opposing effect, as well as contradictory interaction of wollastonite and chicken feathers on the fire properties.

Cluster analysis of fire performance attributes of the six MDF panel treatments showed that panels with $10 \%$ chicken feathers had distinctly different attributes (Figure 1). Previous studies showed that the same level of feathers negatively affected physical and mechanical properties, supporting the premise that addition of too much feather material was detrimental to a range of panel properties [3]. However, addition of wollastonite to the panels helped mitigate these effects on fire performance. The effect of wollastonite on fire properties was also distinguished in panels with no chicken feathers, supporting previous studies on the use of this additive to improve panel properties.

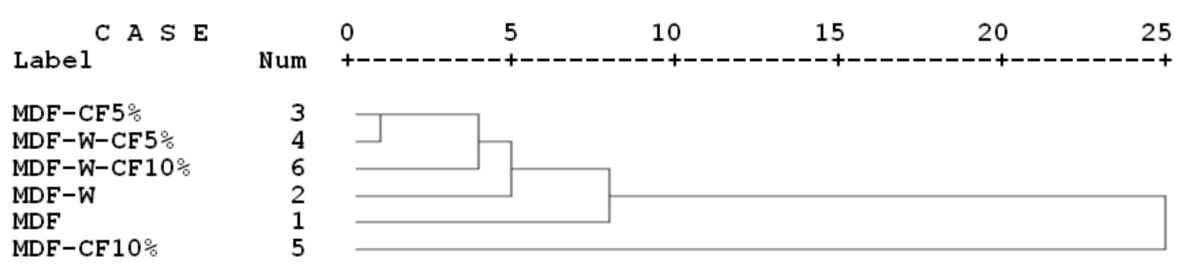

Figure 1. Cluster analysis of the effect of chicken feathers (CF) and wollastonite (W) on fire performance properties of wood-based medium density fibreboard (MDF).

\section{Conclusions}

The addition of small amounts of feathers to wood-based MDF had no significant negative effects on fire performance; that is, addition of $5 \%$ of feather did not make panels more flammable in comparison to the control panels. However, increasing the feather level to $10 \%$ decreased fire resistance. Addition of wollastonite improved fire performance of all MDF panels, but could not completely overcome the negative effects at $10 \%$ feather addition. The negative effects of feathers on panel fire performance were attributed to the lack of integration between the resin, wood and feathers, resulting in a tendency for feather elements near the surface to ignite and expose more material beneath. The results suggest that feathers can be used to a limited extent as a wood substitute, but higher levels are detrimental to fire performance.

Author Contributions: Methodology, H.R.T. and A.N.P.; Validation, H.R.T., J.J.M. and A.N.P.; Investigation, H.R.T.; Writing-Original Draft Preparation, H.R.T., J.J.M., and A.N.P.; Writing-Review and Editing, H.R.T., J.J.M., and A.N.P.; Visualization, H.R.T.; Supervision, H.R.T. and A.N.P. All authors have read and agreed to the published version of the manuscript.

Funding: This research received no external funding.

Institutional Review Board Statement: Not applicable.

Informed Consent Statement: Not applicable.

Data Availability Statement: The data presented in this study are available on request from the corresponding author.

Acknowledgments: The first author appreciates constant scientific support of Jack Norton (Retired, Horticulture \& Forestry Science, Queensland Department of Agriculture, Forestry and Fisheries, Australia), as well as Alexander von Humboldt Stiftung (Bonn, Germany).

Conflicts of Interest: The authors declare no conflict of interest. 


\section{References}

1. Tesfaye, T.; Sithole, B.; Ramjugernath, D. Valorisation of chicken feathers: A review and recovery route-Current status and future prospects. Clean Technol. Environ. Policy 2017, 19, 2363-2378. [CrossRef]

2. Kock, J.W. Physical and Mechanical Properties of Chicken Feather Materials. Master's Thesis, School of Civil Environmental Engineering, Georgia Institute of Technology, Atlanta, GA, USA, 2006.

3. Taghiyari, H.R.; Majidi, R.; Esmailpour, A.; Sarvari Samadi, Y.; Jahangiri, A.; Papadopoulos, A.N. Engineering composites made from wood and chicken feather bonded with UF resin fortified with wollastonite: A novel approach. Polymers 2020, $12,857$. [CrossRef] [PubMed]

4. Taghiyari, H.R. Fire-Retarding Properties of Nano-Silver in Solid Woods. Wood Sci. Technol. 2012, 46, 939-952. [CrossRef]

5. Taghiyari, H.R.; Norton, J.; Tajvidi, M. Effects of Nano-materials on Different Properties of Wood-Composite Materials. In Bio-Based Wood Adhesives: Protection, Characterization, and Testing; CRC Press/Taylor \& Francis Group: Boca Raton, FL, USA, 2016; Chapter 14.

6. Taghiyari, H.R.; Tajvidi, M.; Taghiyari, R.; Mantanis, G.I.; Esmailpour, A.; Hosseinpourpia, R. Nanotechnology for wood quality improvement and protection. In Nanomaterials for Agriculture and Forestry Application; Elsevier: Amsterdam, The Netherlands, 2020; Chapter 19. [CrossRef]

7. Taghiyari, H.R.; Esmailpour, A.; Majidi, R.; Morrell, J.J.; Mallaki, M.; Militz, H.; Papadopoulos, A.N. Potential use of wollastonite as a filler in UF resin based medium-density fiberboard (MDF). Polymers 2020, 12, 1435. [CrossRef] [PubMed]

8. Esmailpour, A.; Taghiyari, H.R.; Majidi, R.; Babaali, S.; Morrell, J.J.; Mohammadpanah, B. Effects of adsorption energy on air and liquid permeability of nanowollastonite-treated medium-density fiberboard. IEEE Trans. Instrum. Meas. 2021, 70, 1-8. [CrossRef]

9. Figueroa, M.; Bustos, C.; Dechent, P.; Reyes, L.; Cloutier, A.; Giuliano, M. Analysis of rheological and thermo-hygro-mechanical behaviour of stress-laminated timber bridge deck in variable environmental conditions. MaderasCienc. Tecnol. 2012, 14, 303-319.

10. ISO 11925-3: 1997. Cor. 1: 1998. Reaction to Fire Tests. Ignitability of Building Products Subjected to Direct Impingement of Flame. Part III: Multi-Source Test; BSI: London, UK, 1998; ISBN 0580292258. 